\title{
Optimization of nuclear magnetic resonance and gas chromatography-mass spectrometry-based fingerprinting methods to characterize goat milk powder
}

\author{
Lorraine Jane Sanchez, ${ }^{1} \oplus$ Dan Zhu, ${ }^{2} \odot$ Russell Frew, ${ }^{2} \oplus$ and Biniam Kebede ${ }^{1 *}$ () \\ ${ }^{1}$ Department of Food Science, University of Otago, Dunedin 9016, New Zealand \\ ${ }^{2}$ Department of Chemistry, University of Otago, Dunedin 9016, New Zealand
}

\begin{abstract}
This study is the first to provide a comprehensive characterization of the liquid and volatile fractions of whole goat milk powder (GMP). Robust nuclear magnetic resonance (NMR)- and gas chromatography-mass spectrometry (GC-MS)-based chemical fingerprinting methods were optimized and implemented. The untargeted ${ }^{1} \mathrm{H}-\mathrm{NMR}$ analysis resolved 44 metabolites in the liquid fractions of GMP. The NMR fingerprinting technique effectively identified metabolites coming from the aliphatic, sugar, and aromatic regions that can be important in defining the technological properties and quality of the GMP. The untargeted headspace gas chromatography-mass spectrometry fingerprinting was able to detect a total of 50 volatiles including alkanes, ketones, alcohols, aromatics, alkenes, aldehydes, esters, acid, and sulfur compounds. The GMP was dominated by volatiles in the alkane group, while only a few esters were detected. Goat milk is a premium product and vulnerable to fraudulent activities such as adulteration or counterfeit. Therefore, proper characterization and identification is a crucial first step to verify its authenticity and quality.

Key words: whole goat milk powder, nuclear magnetic resonance fingerprinting, gas chromatography-mass spectrometry fingerprinting, method optimization, milk characterization, identification
\end{abstract}

\section{INTRODUCTION}

Goat milk has become increasingly popular due to its high nutritional value and quality. It is considered a viable alternative for cow milk and delivers many nutrients relevant to the consumer's health. This milk type

Received March 3, 2020.

Accepted August 25, 2020.

*Corresponding author: biniam.kebede@otago.ac.nz is primarily used as a nutritional source for infants and children as well as a medicinal food (Raynal-Ljutovac et al., 2008; Silanikove et al., 2010). In recent studies, it has been shown as a satisfactory probiotic carrier during storage due to its properties that could facilitate long-term survival of probiotics. This includes suitable $\mathrm{pH}$, good buffering capacity, and high level of nutrients (Ranadheera et al., 2018). Moreover, other goat milk products, such as fermented goat milk beverages, have the potential to diversify functional dairy products due to the above-mentioned health benefits of goat milk (Mituniewicz-Małek et al., 2019).

As milk production increases worldwide, goat milk has also been commonly processed into milk powder, making it easier to store and transport. This dehydration process has attracted interest from the dairy industry because it can greatly extend the shelf life of milk and still preserve its nutritional and sensory properties. Producing milk in powder form has likewise significantly contributed to the increasing economy in some exporting countries (Thomas et al., 2004; Fonseca et al., 2011). Despite numerous studies on other milk types, the data for whole goat milk powder (GMP) is still limited. According to Haenlein (2007), researchers in most studies targeted specific quality-related characteristics such as minerals and vitamins. The unique compositions specifically found in GMP, which could be used to define its identity and maximize its potential, have not been fully explored yet. Furthermore, goat milk is a premium product and vulnerable to fraudulent activities such as adulteration or counterfeit. Therefore, proper characterization is an important first step to verify its authenticity and quality.

Recent advances in analytical techniques offer huge potential to address this research gap. One of the analytical approaches is chemical fingerprinting. It is a comprehensive and unbiased technique, which considers the vast number of compounds present in the investigated food fraction instead of targeting specific components, with the aim of obtaining a broad understanding of the product. This strategy uses advanced analytical instruments, such as MS and nuclear magnetic reso- 
nance (NMR). These 2 techniques can generate huge amounts of food compositional data and can lead to the determination of unique and marker chemical compounds (Cifuentes, 2013).

For the first time in literature, this study optimized and implemented NMR- and GC-MS-based fingerprinting approach to comprehensively characterize GMP. These techniques are suitable in studying milk compositions both in the liquid and headspace (HS) fraction. First, NMR provides a survey of the milk metabolome in the liquid fraction, which is important because most nutrients can be easily extracted in this milk portion. Nuclear magnetic resonance has been shown as a powerful tool for nondestructive and rapid identification of diverse groups of secondary metabolites as well as abundant primary metabolites. Moreover, HS-GC-MS is a powerful technique to obtain the volatile fingerprint of GMP. Studying volatiles is important in understanding the aroma and flavor characteristics in milk $(\mathrm{Hu}$ et al., 2004; Wishart, 2008; Kim et al., 2010; Vagenas and Roussis, 2012; Vervoort et al., 2012). Because volatiles are often involved in important process-induced reactions (e.g., Maillard reaction, Strecker degradation, lipid oxidation), the HS fractions can be used as indicators of the processing and subsequent storage effects, which can be useful in the dairy industry. Therefore, this research strives to optimize and implement NMRand GC-MS-based fingerprinting methods to characterize GMP.

\section{MATERIALS AND METHODS}

\section{Reagents and Samples}

Deuterium oxide $(99.9 \%)$ was obtained from Cambridge Isotope Laboratories (College Park, MD). Sodium 3-(trimethylsilyl) propionate-2,2,3,3- $\mathrm{d}_{4}$ (TSP) was purchased from Sigma-Aldrich (St Louis, MO). Spray-dried GMP samples were obtained from NIG Nutritionals Limited (Waikato, New Zealand). For the spray-drying, air temperature entering the chamber was around $180^{\circ} \mathrm{C}$ and product falling into the fluidized bed dryer was around $60^{\circ} \mathrm{C}$, which was further cooled to $40^{\circ} \mathrm{C}$. After arrival at the University of Otago, fresh samples were immediately packed in 50-mL Falcon tubes and stored in $-30^{\circ} \mathrm{C}$ in a dark environment until analysis. All analyses were performed using the same batch of GMP. Before analysis, frozen samples were thawed for at least $1 \mathrm{~h}$ in the cooling room $\left(4^{\circ} \mathrm{C}\right)$. Solid phase microextraction (SPME) fibers (50/30 $\mu \mathrm{m}$ divinylbenzene/carboxen/polydimethylsiloxane; StableFlex, Supelco, Bellefonte, PA) were conditioned every first use according to manufacturer's instructions.

\section{The ${ }^{1} H-N M R$ Analysis}

Sample Extraction and Preparation. Sample extraction was done to remove high molecular weight compounds that may mask the signal of the components found in the milk samples. A prior sample extraction optimization was done using different organic solvents including methanol, ethanol, chloroform, and methanol-chloroform mixture. The solvents were tested for their ability to extract a huge number of metabolites in GMP. Among the organic solvents tested for extraction, methanol was found to produce high quality spectra with many visible peaks of compounds in the milk sample. Moreover, the use of methanol offered a simple and rapid sample extraction protocol, which can be very useful in a large-scale analysis. Thus, methanol was considered as the final extraction solvent for the NMR analysis.

The NMR sample extraction and experiments were performed based on the method reported by Zhu et al. (2020) with some modifications. During sample extraction, 4 replicates of $1.0 \mathrm{~g}$ of GMP was dissolved in 4 $\mathrm{mL}$ of distilled water and centrifuged at $4,696 \times g$ for 30 min at $4^{\circ} \mathrm{C}$ (Heraeus Megafuge 16R; Thermo Fisher Scientific, Waltham, MA). The supernatants were then collected, and $0.5 \mathrm{~mL}$ was taken to a new centrifuge tube. One milliliter of methanol was added to the skim milk and placed in a Heidolph Multi Reax (Schwabach, Germany) mechanical stirrer for 15 min, centrifuged again at $4,696 \times g$ for $10 \mathrm{~min}$ at $4^{\circ} \mathrm{C}$, and then dried under a Vacuubrand ME 1C vacuum pump (Vacuubrand GmbH, Wertheim, Germany). The dried samples were redissolved with $700 \mu \mathrm{L}$ of deuterium oxide $(0.1 \mathrm{M}$ phosphate buffer, $\mathrm{pH}=7.4,5 \mathrm{mMTSP}$ ) and sonicated for $10 \mathrm{~min}$ to further dissolve the samples. The TSP served as the internal standard and reference for the calibration of NMR shifts, while phosphate buffer was used to maintain the $\mathrm{pH}$ of the extracts to avoid signal shifts. The samples were centrifuged again at $4,696 \times$ $g$ for $5 \mathrm{~min}$ at $4^{\circ} \mathrm{C}$, and $600 \mu \mathrm{L}$ of clear liquid was taken to a 5-mm NMR tube (Norell ST500; Norell Inc., Morganton, NC) for analysis.

The ${ }^{1} \boldsymbol{H}$-NMR Experiments. The NMR experiments were performed using a Varian $500 \mathrm{MHz}$ spectrometer (Agilent Technologies, Santa Clara, CA). The ${ }^{1} \mathrm{H}-\mathrm{NMR}$ spectra of milk extracts were acquired using a $6-\mathrm{kHz}$ spectral width and $64-\mathrm{K}$ data point with $90^{\circ}$ pulse sequence, 2 s relaxation delay, and 128 scan numbers, requiring about $12 \mathrm{~min}$ per sample. These NMR sample preparation procedures were optimized to detect as many metabolites as possible. The NMR spectra processing was carried out using MestReNova NMR software (version 12.0.3, Mestrelab Research, 
Santiago de Compostela, Spain). Autophase correction and manual baseline correction were done to correct distortions. The spectra were then referenced to TSP at a chemical shift $(\delta)$ of $0.0 \mathrm{ppm}$.

Identification of impurities or solvent peaks was performed, and those peaks were disregarded before qualification of possible metabolites in the GMP samples. Multiplet analysis was performed, and assignment of signals was done by comparing the chemical shifts in the NMR spectra with the data from previous studies (Sundekilde, 2012; Sundekilde et al., 2013a; Li et al., 2017; Zhao et al., 2017) and from the Human Metabolome Database (HMDB; http://www.hmdb.ca/) and Chenomx NMR suite 8.43 (Chenomx Inc, Edmonton, AB, Canada).

\section{Headspace SPME GC-MS Analysis}

Sample Preparation. To detect as many volatiles as possible, sample preparation and method optimization were done before final volatile analysis. Different sample preparations were tested including milk powder in solid form and reconstituted milk in water as well as the effect of adding salt $(\mathrm{NaCl})$. We chose the method using a milk powder as it resulted in a greater number of peaks and overall higher intensity. A total of $2.0 \pm$ $0.03 \mathrm{~g}$ of milk powder samples were transferred into 20-mL glass sample vials; lids were tightly closed using screwcaps with silicon septum seal (GRACE, Columbia, MD) septa.

The GC-MS Analysis. The HS analysis was performed based on the method reported by Kebede et al. (2015) with slight modifications. First, a total of 2.0 $\pm 0.03 \mathrm{~g}$ of milk powder samples were transferred into 20-mL glass sample vials (GRACE). The sample vials were then placed in a 32-vial cooled tray (VT32-20) on a Gerstel MPS autosampler (Gerstel GmbH, Mülheim an der Ruhr, Germany) maintained at $10^{\circ} \mathrm{C}$ and analyzed by GC-MS Agilent Technologies $6890 \mathrm{~N}$ gas chromatograph equipped with a MS (Agilent Technologies, 5975B VL MSD). The GMP samples in a vial were incubated at $40^{\circ} \mathrm{C}$ for $5 \mathrm{~min}$. Then, extraction using SPME fiber coated with $50 / 30 \mu \mathrm{m}$ divinylbenzene/ carboxen/polydimethylsiloxane was performed at $40^{\circ} \mathrm{C}$ for $30 \mathrm{~min}$. We chose this SPME fiber coating due to its ability to detect an increased number of volatile compounds coming from a broad range of chemical families. Following extraction, the SPME fiber was thermally desorbed in the GC-inlet at $230^{\circ} \mathrm{C}$ for $2 \mathrm{~min}$ in splitless mode, followed by a further 5 min with a purge flow of $50 \mathrm{~mL} / \mathrm{min}$. The analytical column (ZB Wax, $60 \mathrm{~m} \times 0.32 \mathrm{~mm}$ inner diameter $\times 0.5 \mu \mathrm{m}$ film thickness; Phenomenex, Torrance, CA), using helium as a carrier gas, was used to separate the volatiles. The initial oven temperature was $50^{\circ} \mathrm{C}$, held for 5 min, a $5^{\circ} \mathrm{C} / \mathrm{min}$ ramp until $210^{\circ} \mathrm{C}$, followed by a $10^{\circ} \mathrm{C} /$ min ramp to $240^{\circ} \mathrm{C}$, and held for $5 \mathrm{~min}$. Compound detection was performed using mass in electron ionization mode $(70 \mathrm{eV})$, scanning from 30 to $300 \mathrm{~m} / z$. The source and quadrupole were operated at $230^{\circ} \mathrm{C}$ and $150^{\circ} \mathrm{C}$, respectively.

The GC-MS Data Analysis. Identification of volatiles was performed using the standard NIST14 mass spectral library MS library (https://chemdata .nist.gov/) match $(\geq 80)$ supported by linear retention indices, as calculated according to van Den Dool and Dec. Kratz (1963) from injection of a $1 \mu \mathrm{g} / \mathrm{mL}$ C7-C24 alkane standard (Supelco) in hexane, and by chemical standards. By using these related standards, uniformity in the retention behavior during identification of volatiles can be best described by retention indices. The identification was performed using pure spectra after peak deconvolution using automated mass spectral deconvolution and identification system. The literature retention indices used for comparison were obtained from the NIST Standard Reference Database according to the most similar system and instrument (GC column) conditions.

\section{RESULTS AND DISCUSSION}

\section{Identification of Goat Milk Liquid Fraction with ${ }^{1} \mathrm{H}-\mathrm{NMR}$}

In untargeted ${ }^{1} \mathrm{H}-\mathrm{NMR}$ analysis, the identification of milk metabolites is the most important but challenging step. It requires time and skills, particularly when many overlapping peaks are present. When assigning signals, it should be noted that the different hydrogen nucleus in each metabolite produces an NMR signal at a specific resonance frequency. This is measured as a chemical shift relative to a standard compound (Dona et al., 2016). As shown in Figure 1, the ${ }^{1} \mathrm{H}-\mathrm{NMR}$ spectrum is divided into 3 main spectral regions. First, the aliphatic region, from 0 up to $3.5 \mathrm{ppm}$, contains AA, tricarboxylic acid cycle intermediates, short-chain fatty acids, N-acetyl moieties, and oligosaccharides. This is followed by the region between 3.5 and $6.0 \mathrm{ppm}$, which is a complex sugar region that includes a series of overlapped signals due to the presence of simple and complex sugars. Finally, the region after $6.0 \mathrm{ppm}$ is the aromatic region composed of aromatic AA and phenolic compounds (Praticò et al., 2014). Identifying the different regions in the spectra allows for easier classification of signals into metabolites. Compounds are also classified according to class type or multiplicity. 


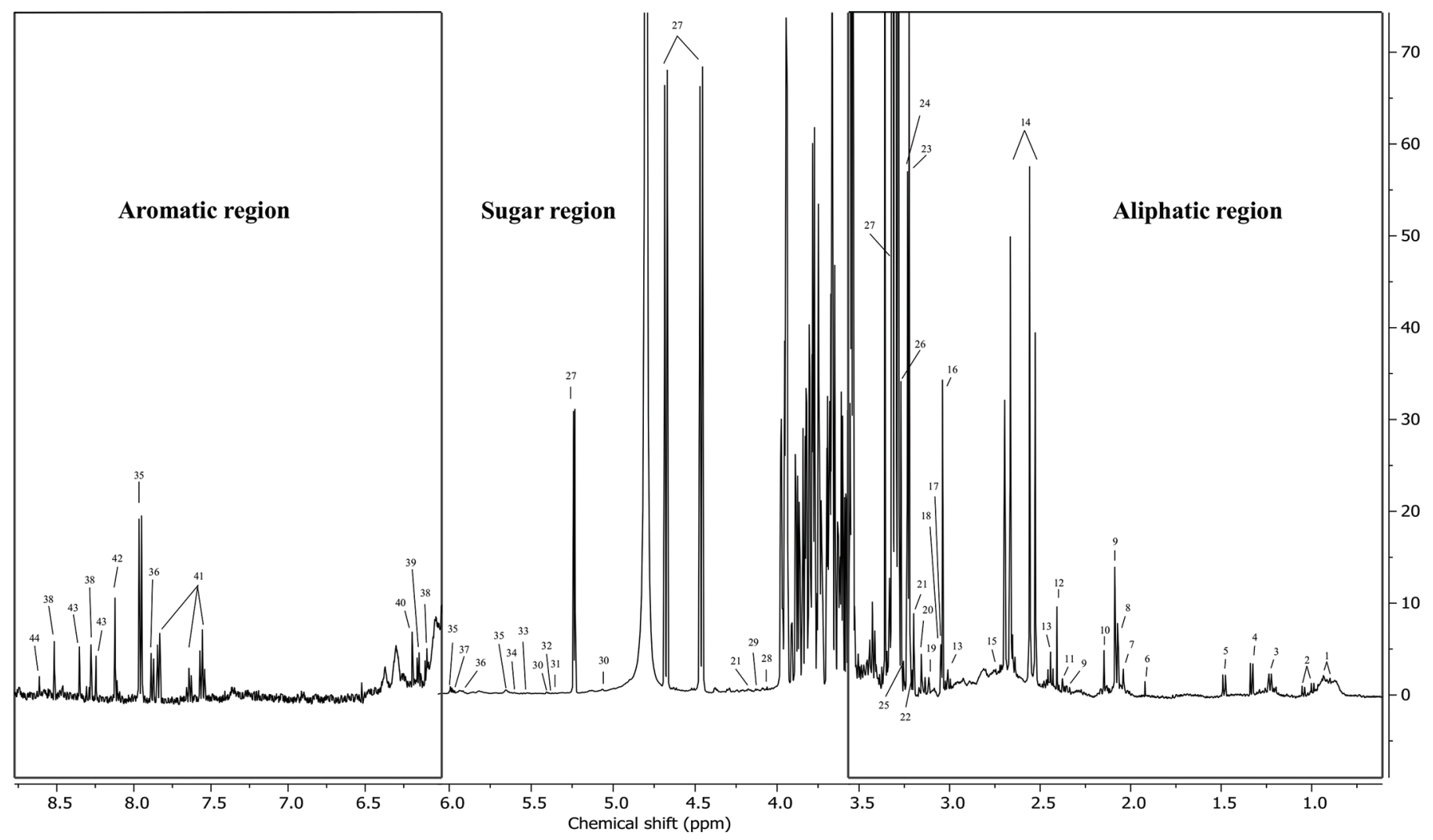

Figure 1. Representative ${ }^{1} \mathrm{H}$ nuclear magnetic resonance spectra of goat milk powder divided into 3 main groups. The regions $\delta 9.0-6.0$ and $\delta 3.5-0.0$ were expanded for clarity of peaks. Numbers correspond to the metabolites shown in Table 1.

Understanding these enables further accurate profiling of the NMR resonances.

In the present work, a total of 44 metabolites were identified based on the ${ }^{1} \mathrm{H}-\mathrm{NMR}$ spectra of New Zealand GMP. Table 1 summarizes the NMR metabolite assignments. The GMP spectra are dominated by the signals in the aliphatic and sugar regions, which correspond to metabolites such as creatine, carnitine, lactose, galactose, lecithin and sucrose. Li et al. (2017) reported higher concentrations of carnitine and creatine in UHT goat milk. However, the study was more targeted on high-intensity peaks, thereby it identified only a few metabolites. In the current study, some lessintensive signals were visible and identified in the aliphatic (0.5-3.5) and aromatic regions (6.0-9.5) of GMP spectra, including AA, organic acids, and nucleotides. According to $\mathrm{Hu}$ et al. (2004), a possible reason for the weak signals could be due to the very large molecular weights of the proteins, which results in lower molar concentrations. However, this does not mean that lowintensity metabolites are not important. For example, in the study of Sundekilde et al. (2013b), lactate and BHB were some of the metabolites which increased in relative quantification in cow milk with high levels of SCC, while hippuric acid decreased. The SCC is an important indication of mastitis infection, and it has a strong correlation with NMR milk metabolite profiles. With this, it is essential to characterize as many metabolites as possible in GMP to discriminate it from other types of milk. Other metabolites found in GMP such as valine, pantothenate, citric acid, lactic acid, betaine, and creatinine were also found at high levels in the colostrum and transitional human milk. This data can be useful in establishing the milk metabolome for infant nutrition specifically with preterm infants (Sundekilde et al., 2016). These examples show the importance of a wide-range characterization of metabolites. Furthermore, the data obtained from this untargeted characterization can be used to carry a more targeted or pseudotargeted research on the composition of GMP. This can include research on metabolite concentrations partnered with chemometric tools, which can further define the different technological properties of milk powder. Moreover, this study is the first to successfully provide a comprehensive characterization of the liquid fraction of New Zealand GMP. 
Table 1. Metabolites assignment from ${ }^{1} \mathrm{H}$ nuclear magnetic resonance spectra of the New Zealand goat milk powder

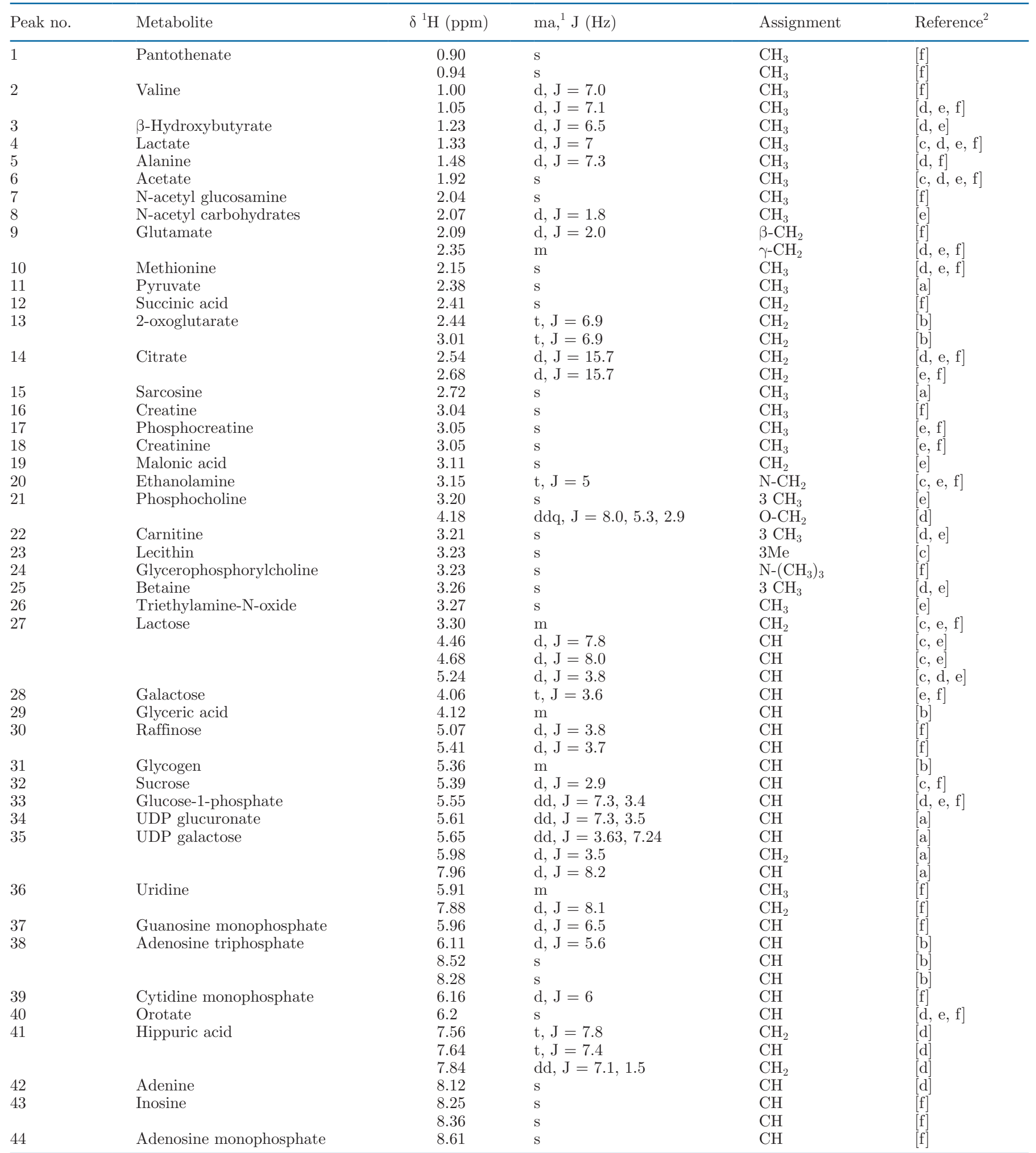

${ }^{1} \mathrm{ma}=$ class/multiplicity; $\mathrm{s}=$ singlet; $\mathrm{d}=$ doublet; $\mathrm{t}=$ triplet; $\mathrm{dd}=$ doublet of doublets; $\mathrm{ddq}=$ doublet of doublet of quartet; $\mathrm{m}=$ multiplet. ${ }^{2}[\mathrm{a}]=$ Chenomx NMR Suite 8.43 (Chenomx Inc, Edmonton, AB, Canada); [b] = Human Metabolome Database (HMDB; http://www.hmdb.ca/ ); [c] = Li et al. (2017); [d] = Sundekilde (2012); [e] = Sundekilde et al. (2013a); [f] = Zhao et al. (2017). 
The Volatile Fingerprint of GMP: An HS-SPME-GC-MS Analysis

The optimized HS-SPME-GC-MS method obtained the detection of 50 volatiles in GMP, which are classified into 9 chemical families (Table 2). Most of the volatiles are from aliphatic hydrocarbons, such as alkanes, with a total of 26 compounds followed by 8 ketones, 4 alcohols, 3 aromatics, 3 alkenes, 2 aldehydes, 2 esters, 1 acid, and 1 sulfur-compound. A representative chromatogram can be seen in Figure 2. According to our knowledge, there are no studies in the literature investigating the volatile profile of GMP. Hence, discussion and interpretation of each chemical classes was performed by comparing them to other goat milk-based products (e.g., raw or pasteurized).

Aliphatic Hydrocarbons. Alkanes are the most abundant volatiles found in this study, with around half of the detected compounds classified in this group. Yue et al. (2015) also detected more aliphatic hydrocarbons in identifying microfiltered pasteurized milk volatiles using SPME-GC $\times$ GC time-of-flight MS. Other studies suggest that due to the hemolytic cleavage of carbon-carbon bonds along the fatty acid chains in hightemperature conditions, an increased number of alkanes can be formed in boiled or heated milk (Iranmanesh et al., 2018). This justifies the observations in this study because GMP had undergone heat processing. In general, alkanes have a minor effect on the overall milk flavor due to their high odor threshold level (Moio et al., 1993; Yue et al., 2015). Alkanes were also reported in other dairy products containing goat milk. Erkaya and Şengul (2011) studied volatiles in yogurts produced from goat milk and identified n-alkanes similar to the volatiles found in this study including heptane, octane, decane, nonane, and undecane, where heptane showed highest concentrations. Moio et al. (1993) reported decane, undecane, tetradecane, and traces of dodecane, tridecane, pentadecane, and hexadecane from raw goat milk, which also corresponds to the findings in this study.

Ketones. Ketones are abundant in most dairy products (Delgado et al., 2011). They are mainly present in the form of methyl ketones, which are products of free fatty acids (FFA) through the $\beta$-oxidation pathway. Methyl ketones can also be formed as a result of thermally induced reactions. Previous studies have reported that they are formed and increase in concentration after thermal treatment of milk (Calvo and de la Hoz, 1992; Moio et al., 1993; Vazquez-Landaverde et al., 2006).

Ketones have distinctive odors, such as fruity, floral, and musty notes, that contribute to the flavor of milk. One of the ketones found in this study, 2-heptanone, is a typical volatile compound in dairy products (Pan et al., 2019). Some of the methyl ketones found in this study such as acetone, 2-pentanone, 2-heptanone, and 2-nonanone have also been reported in raw milk, while others were detected in heated milk (UHT, sterilized, and powdered milk; Calvo and de la Hoz, 1992). According to Calvo and de la Hoz (1992) and Yue et al. (2015), acetone concentration variation in raw milk could be due to the amount of acetone in feed, while 2 -pentanone and 2-heptanone are partly thermally induced through $\beta$-oxidation of FFA, as discussed earlier. Other ketones found in this study such as 2-nonanone and 2-heptanone have a common fruity flavor. 2-Nonanone corresponds to tea-like, medicinal, or sour notes, whereas 2-heptanone presents a blue cheese or mushroom flavor (Trani et al., 2016).

Alcohols. Alcohols are formed by either a reduction from the aldehydes, AA metabolism, or fermentation of lactose. This chemical class is responsible for the distinct flavors in dairy products when present at high concentrations (Yue et al., 2015). Moio et al. (1993) reported the different levels of alcohols in different types of milk and found that raw goat milk had the secondlowest concentrations compared with the other 3 types of milk (water buffalo, ovine, and bovine). Aldehydes and $\mathrm{AA}$ are responsible for the formation of alcohols. This could explain why there are only limited alcohol compounds present in New Zealand GMP, as there are only a few aldehydes and AA in this milk type at this stage of the study.

Aromatic Compounds. Aromatic hydrocarbons, such as benzene and toluene, have been widely identified in reconstituted milk and reduced-fat cheese (Yue et al., 2015). In this work, toluene was one of the aromatic compounds found in the HS of GMP (Table 2). This compound, which provides nutty odor, was the most abundant and was already identified at high levels in Feta-type and Spanish ewe's milk semihard cheeses (Delgado et al., 2011). Some aromatic compounds are derived from the Strecker reaction, such as $\alpha$-oxidation of phenylacetaldehyde, which is responsible for the benzaldehyde production that imparts aromatic notes of bitter almond to dairy products (Yue et al., 2015).

Aldehydes. Aldehydes could provide significant aromas, either pleasant or rancid, to foodstuff depending on their concentration. In comparison to alcohols, they have lower odor threshold values. Thus, even trace amounts of aldehydes might override the flavor effect of some other substances (Yue et al., 2015). In processed milk products, the formation of aldehydes is mostly associated with thermally induced lipid oxidation (Calvo and de la Hoz, 1992). One of the aldehydes found in this study was hexanal. It has a green and grassy aroma, also known to contribute off-flavors in milk at higher concentrations (Yue et al., 2015). Generally, aldehydes 
Table 2. Volatile profile of the New Zealand goat milk powder obtained by the headspace GC-MS fingerprinting method

\begin{tabular}{|c|c|c|c|}
\hline \multirow[b]{2}{*}{ Item } & \multirow[b]{2}{*}{ Compound } & \multicolumn{2}{|c|}{ Retention index $(\mathrm{RI})^{1}$} \\
\hline & & Observed & Reference \\
\hline \multicolumn{4}{|c|}{ Alcohols } \\
\hline 1 & Isopropyl alcohol & 921 & 927 \\
\hline 2 & Ethanol & 930 & 932 \\
\hline 3 & 2-Butyloctanol & 1,104 & 1,393 \\
\hline 4 & Ethylhexanol & 1,483 & 1,491 \\
\hline \multicolumn{4}{|c|}{ Alkanes } \\
\hline 5 & Hexane & 651 & 600 \\
\hline 6 & Cyclopentane & 666 & 700 \\
\hline 7 & 2,5-Dimethylhexane & 712 & 721 \\
\hline 8 & 2-Methylheptane & 750 & 765 \\
\hline 9 & 2,3,3-Trimethylpentane & 766 & 758 \\
\hline 10 & Octane & 800 & 800 \\
\hline 11 & 2,4-Dimethylheptane & 806 & 797 \\
\hline 12 & 2,2,4-Trimethylheptane & 842 & 884 \\
\hline 13 & 4-Methyloctane & 852 & 823 \\
\hline 14 & Nonane & 899 & 900 \\
\hline 15 & 2-Methylnonane & 951 & 961 \\
\hline 16 & 3-Methylnonane & 963 & 970 \\
\hline 17 & 2,2,4,6,6-Pentamethylheptane & 984 & 981 \\
\hline 18 & Decane & 998 & 1,000 \\
\hline 19 & 2,6-Dimethylnonane & 1,005 & 986 \\
\hline 20 & 5-Methyldecane & 1,047 & 1,049 \\
\hline 21 & 4-Methyldecane & 1,051 & 1,051 \\
\hline 22 & 2,6-Dimethyldecane & 1,089 & 1,086 \\
\hline 23 & Undecane & 1,097 & 1,100 \\
\hline 24 & 5-Ethyldecane & 1,134 & 1,150 \\
\hline 25 & Methylundecane & 1,146 & 1,150 \\
\hline 26 & 2-Methylundecane & 1,153 & 1,155 \\
\hline 27 & 2,6-Dimethylundecane & 1,193 & 1,185 \\
\hline 28 & Dodecane & 1,197 & 1,200 \\
\hline 29 & Farnesan & 1,242 & 1,320 \\
\hline 30 & Tetradecane & 1,396 & 1,400 \\
\hline \multicolumn{4}{|l|}{ Acid } \\
\hline 31 & 2-Oxooctanoic acid & 877 & 1,309 \\
\hline \multicolumn{4}{|c|}{ Aldehydes } \\
\hline 32 & Hexanal & 1,084 & 1,083 \\
\hline 33 & Heptanal & 1,187 & 1,184 \\
\hline \multicolumn{4}{|c|}{ Alkenes } \\
\hline 34 & 2-Octene & 837 & 850 \\
\hline 35 & 2-Ethylhexene & 864 & 847 \\
\hline 36 & 2,4-Dimethyl-1-heptene & 880 & 885 \\
\hline \multicolumn{4}{|c|}{ Aromatics } \\
\hline 37 & Toluene & 1,044 & 1,042 \\
\hline 38 & Cyclooctatetraene & 1,263 & 1,244 \\
\hline 39 & 1,3-Ditertiarybutylbenzene & 1,431 & 1,427 \\
\hline \multicolumn{4}{|c|}{ Esters } \\
\hline 40 & Diisoamyl & 911 & 887 \\
\hline 41 & Methyl succinate & 1,590 & 1,572 \\
\hline \multicolumn{4}{|c|}{ Ketones } \\
\hline 42 & Acetone & 817 & 819 \\
\hline 43 & 2-Pentanone & 979 & 981 \\
\hline 44 & 2-Heptanone & 1,183 & 1,182 \\
\hline 45 & Cyclohexanone & 1,301 & 1,291 \\
\hline 46 & Diacetone & 1,364 & 1,358 \\
\hline 47 & 2-Nonanone & 1,390 & 1,390 \\
\hline 48 & 3-Octen-2-one & 1,411 & 1,411 \\
\hline 49 & 3,5-Octadiene-2-one & 1,523 & 1,522 \\
\hline \multicolumn{4}{|c|}{ Sulfur compounds } \\
\hline 50 & Dimethyl sulfone & 1,910 & 1,903 \\
\hline
\end{tabular}

${ }^{1}$ Observed RI calculated according to van Den Dool and Dec. Kratz (1963); reference RI obtained from the National Institute of Standards and Technology Standard Reference Database (https://chemdata.nist.gov/). 
of low concentrations are characterized by green and grass-like aromas in milk. Only at a high concentration will it start producing off-flavors in milk and its products (Pan et al., 2019). Future studies should monitor the change in hexanal concentration as a function of processing and subsequent storage conditions.

Esters. Esters are considered as important volatiles in dairy products and known for their powerful odors. Ester formation is usually associated with the esterification of short-chain alcohols and FFA within the mammary gland of the dairy animal (Moio et al., 1993; Kalač, 2017). In the study of Queiroga et al. (2019), fresh goat milk was represented mostly by ester compounds. Several esters were also reported in raw goat milk by Moio et al. (1993). However, in the current study, only 2 ester compounds were identified in the New Zealand GMP using the HS-SPME-GC-MS procedure (Table 2). A similar result was reported in the study of High et al. (2019), where esters were not found in the spray-dried New Zealand sheep milk. It was suspected that high thermal load from pasteurization to subsequent spray-drying of the milk powder had affected the levels of esters by decreasing or eliminating them in milk. As the GMP used in this study underwent similar processing, this may also explain why low levels of esters were found. Future studies need to monitor the change in ester's concentration starting from the fresh GM, during processing up to subsequent storage.
Others: Acids and Sulfur Compounds. One of the important flavor components of dairy products is the FFA. They are produced primarily via lipolysis of milk fat. As mentioned in previous sections, FFA function as precursors for other compounds, making their presence vital (Erkaya and Şengul, 2011; Vagenas and Roussis, 2012). In this GMP, only 1 acid compound was detected. There is a need for further shelf-life studies as these compounds could further increase during storage, as observed in the yogurt study of Erkaya and Şengul (2011).

Sulfur-containing compounds are generally flavoractive constituents in heated milk. They are responsible for the "cooked" off-flavor note, possibly generated during the high-temperature processing. The only sulfurcompound identified among the volatile components of fresh milk in the study of (Moio et al., 1993) was dimethyl sulphone. High et al. (2019) also noted that the SPME technique enables extraction of this small polar compound, which is consistent with the result of the present study.

\section{CONCLUSIONS}

This work has effectively optimized and implemented NMR- and GC-MS-based analytical methods to characterize the liquid and volatile fractions of New Zealand GMP. The untargeted ${ }^{1} \mathrm{H}-\mathrm{NMR}$ analysis was

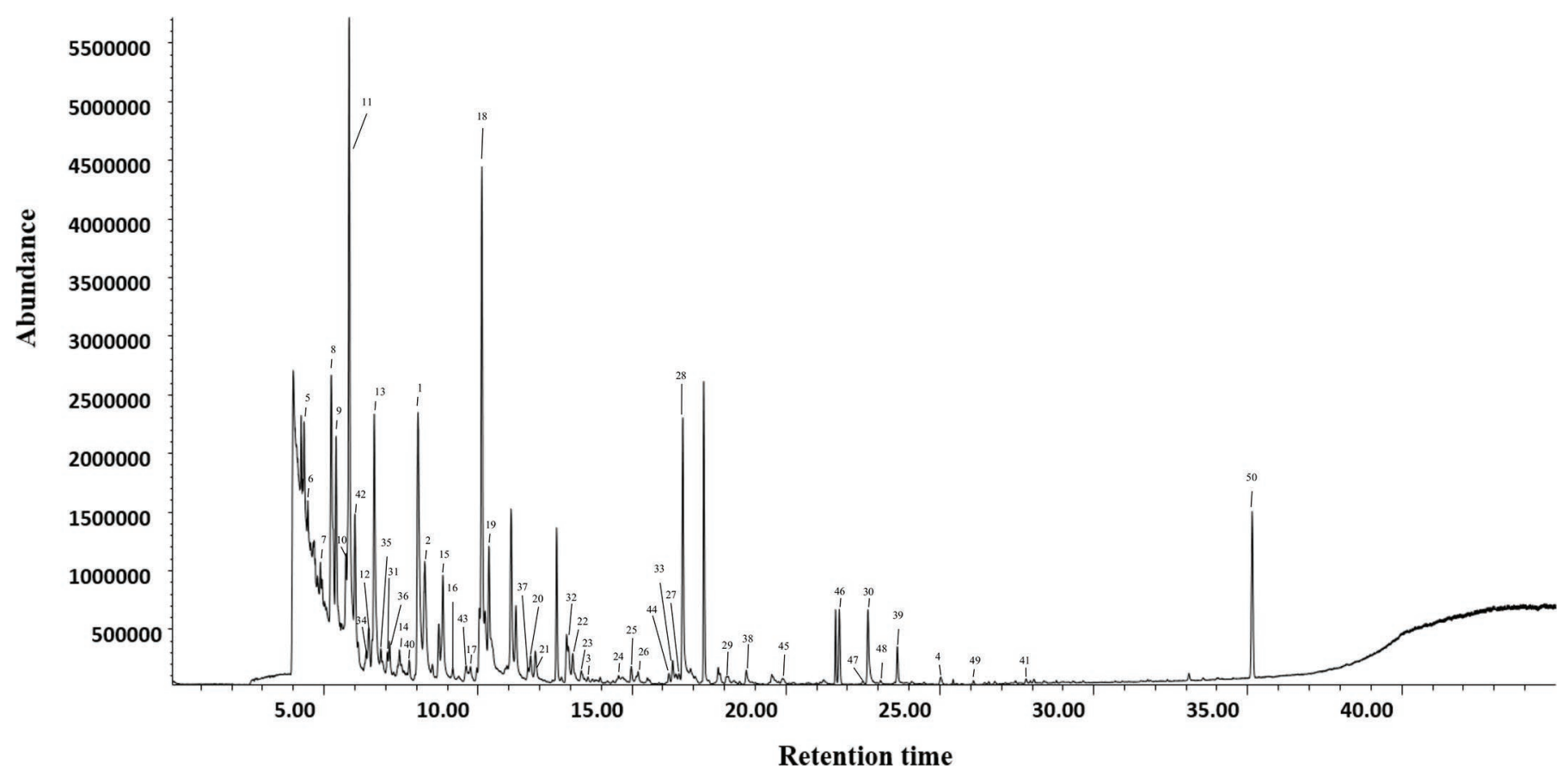

Figure 2. Representative headspace GC-MS chromatogram of New Zealand goat milk powder. Numbers correspond to the volatiles listed in Table 2 . 
able to identify 44 metabolites in the liquid fraction coming from the aliphatic, sugar, and aromatic regions. Likewise, the untargeted HS-SPME-GC-MS method enabled detection of 50 volatiles from a broad range of chemical families, including aliphatic hydrocarbons such as alkanes, with a total of 26 compounds followed by 8 ketones, 4 alcohols, 3 aromatics, 3 alkenes, 2 aldehydes, 2 esters, 1 acid, and 1 sulfur-compound. The present work implemented an effective NMR-based metabolomics approach to characterize the water-soluble fraction of GMP. In the future, there is a need to increase insight into the lipid fraction of the GMP. With respect to aroma and overall flavor, there is a need for a future sensory and GC-olfactometry analysis to investigate the aromatic relevance of the detected volatile compounds. Furthermore, there is a need to investigate the effects of intrinsic (e.g., breed, lactation stage, and season) and extrinsic parameters (e.g., formulation, processing, and storage) on GMP composition to further define its potential and quality.

\section{ACKNOWLEDGMENTS}

Lorraine Jane Sanchez was awarded with a New Zealand-ASEAN Scholarship under the New Zealand Aid Programme (Dunedin, New Zealand) to undertake her Master of Science study. The authors thank Michelle Leus, Ian Stewart, Bonita Manucdoc and Ian Ross (Otago University, Dunedin, New Zealand) for their laboratory assistance, and Pankaj Sharma of NIG Nutritionals Limited (Waikato, New Zealand) for providing the GMP in kind. The authors have not stated any conflicts of interest.

\section{REFERENCES}

Calvo, M. M., and L. de la Hoz. 1992. Flavour of heated milks. A review. Int. Dairy J. 2:69-81. https://doi.org/10.1016/0958 -6946(92)90001-3.

Cifuentes, A. 2013. Foodomics: Principles and applications. Pages 1-13 in Foodomics: Advanced Mass Spectrometry in Modern Food Science and Nutrition. Wiley, Hoboken, NJ.

Delgado, F. J., J. Gonzalez-Crespo, R. Cava, and R. Ramirez. 2011. Formation of the aroma of a raw goat milk cheese during maturation analysed by SPME-GC-MS. Food Chem. 129:1156-1163. https://doi.org/10.1016/j.foodchem.2011.05.096.

Dona, A. C., M. Kyriakides, F. Scott, E. A. Shephard, D. Varshavi, K. Veselkov, and J. R. Everett. 2016. A guide to the identification of metabolites in NMR-based metabonomics/metabolomics experiments. Comput. Struct. Biotechnol. J. 14:135-153.

Erkaya, T., and M. Şengul. 2011. Comparison of volatile compounds in yoghurts made from cows', buffaloes', ewes' and goats' milks. Int. J. Dairy Technol. 64:240-246. https://doi.org/10.1111/j.1471 $-0307.2010 .00655 . \mathrm{x}$

Fonseca, C. R., M. S. G. Bento, E. S. M. Quintero, A. L. Gabas, and C. A. F. Oliveira. 2011. Physical properties of goat milk powder with soy lecithin added before spray drying. Int. J. Food Sci. Technol. 46:608-611. https://doi.org/10.1111/j.1365-2621.2010.02527.x.
Haenlein, G. F. W. 2007. About the evolution of goat and sheep milk production. Small Rumin. Res. 68:3-6. https://doi.org/10.1016/j .smallrumres.2006.09.021.

High, R., P. Bremer, B. Kebede, and G. T. Eyres. 2019. Comparison of four extraction techniques for the evaluation of volatile compounds in spray-dried New Zealand sheep milk. Molecules 24:1917. https: //doi.org/10.3390/molecules24101917.

Hu, F., K. Furihata, M. Ito-Ishida, S. Kaminogawa, and M. Tanokura. 2004. Nondestructive observation of bovine milk by NMR spectroscopy: Analysis of existing states of compounds and detection of new compounds. J. Agric. Food Chem. 52:4969-4974. https:// doi.org/10.1021/jf049616o.

Iranmanesh, M., H. Ezzatpanah, B. Akbari-Adergani, and M. A Karimi Torshizi. 2018. SPME/GC-MS characterization of volatile compounds of Iranian traditional dried Kashk. Int. J. Food Prop. 21:1067-1079. https://doi.org/10.1080/10942912.2018.1466323.

Kalač, P. 2017. Volatiles affecting the flavor of milk and milk products. Pages 175-205 in Effects of Forage Feeding on Milk. Academic Press, Cambridge, MA.

Kebede, B. T., T. Grauwet, J. Magpusao, S. Palmers, C. Michiels, M. Hendrickx, and A. Van Loey. 2015. Chemical changes of thermally sterilized broccoli puree during shelf-life: Investigation of the volatile fraction by fingerprinting-kinetics. Food Res. Int. 67:264-271. https://doi.org/10.1016/j.foodres.2014.10.017.

Kim, H. K., Y. H. Choi, and R. Verpoorte. 2010. NMR-based metabolomic analysis of plants. Nat. Protoc. 5:536-549. https://doi.org/ 10.1038/nprot.2009.237.

Li, Q., Z. Yu, D. Zhu, X. Meng, X. Pang, Y. Liu, R. Frew, H. Chen, and G. Chen. 2017. The application of NMR-based milk metabolite analysis in milk authenticity identification. J. Sci. Food Agric. 97:2875-2882. https://doi.org/10.1002/jsfa.8118.

Mituniewicz-Małek, A., D. Zielińska, and M. Ziarno. 2019. Probiotic monocultures in fermented goat milk beverages - Sensory quality of final product. Int. J. Dairy Technol. 72:240-247. https://doi .org/10.1111/1471-0307.12576.

Moio, L., J. Dekimpe, P. Etievant, and F. Addeo. 1993. Neutral volatile compounds in the raw milks from different species. J. Dairy Res. 60:199-213. https://doi.org/10.1017/S0022029900027515.

Pan, M., L. Tong, X. Chi, N. Ai, Y. Cao, and B. Sun. 2019. Comparison of sensory and electronic tongue analysis combined with HS-SPME-GC-MS in the evaluation of skim milk processed with different preheating treatments. Molecules 24:1650. https://doi .org/10.3390/molecules24091650.

Praticò, G., G. Capuani, A. Tomassini, M. E. Baldassarre, M. Delfini, and A. Miccheli. 2014. Exploring human breast milk composition by nmr-based metabolomics. Nat. Prod. Res. 28:95-101. https:// doi.org/10.1080/14786419.2013.843180 https://www.ncbi.nlm.nih .gov/pubmed/24079341.

Queiroga, R. C. R. E., M. T. S. Leite Neta, R. D. Dutra Sandes, N. Narain, M. Sousa Galvão, M. S. Madruga, and R. Germano Costa. 2019. An insight in key volatile compounds in goat milk based on their odor active values. J. Food Sci. Nutr. Res. 02. https://doi .org/10.26502/jfsnr.2642-1100008.

Ranadheera, C. S., N. Naumovski, and S. Ajlouni. 2018. Non-bovine milk products as emerging probiotic carriers: Recent developments and innovations. Curr. Opin. Food Sci. 22:109-114. https://doi .org/10.1016/j.cofs.2018.02.010

Raynal-Ljutovac, K., G. Lagriffoul, P. Paccard, I. Guillet, and Y. Chilliard. 2008. Composition of goat and sheep milk products: An update. Small Rumin. Res. 79:57-72. https://doi.org/10.1016/ j.smallrumres.2008.07.009.

Silanikove, N., G. Leitner, U. Merin, and C. G. Prosser. 2010. Recent advances in exploiting goat's milk: Quality, safety and production aspects. Small Rumin. Res. 89:110-124. https://doi.org/10.1016/j .smallrumres.2009.12.033.

Sundekilde, U. K. 2012. Milk metabolite variability and heritability and their association with technological properties of bovine milk elucidated by NMR-based metabonomics. PhD thesis. Science and technology, Department of Food Science, Aarhus University, Aarhus, Denmark. 
Sundekilde, U. K., E. Downey, J. A. O'Mahony, C. A. O'Shea, C. A. Ryan, A. L. Kelly, and H. C. Bertram. 2016. The effect of gestational and lactational age on the human milk metabolome. Nutrients 8:304. https://doi.org/10.3390/nu8050304.

Sundekilde, U. K., L. B. Larsen, and H. C. Bertram. 2013a. NMRbased milk metabolomics. Metabolites 3:204-222. https://doi.org/ 10.3390/metabo3020204.

Sundekilde, U. K., N. A. Poulsen, L. B. Larsen, and H. C. Bertram. 2013b. Nuclear magnetic resonance metabonomics reveals strong association between milk metabolites and somatic cell count in bovine milk. J. Dairy Sci. 96:290-299. https://doi.org/10.3168/ jds.2012-5819.

Thomas, M. E., J. Scher, S. Desobry-Banon, and S. Desobry. 2004. Milk powders ageing: Effect on physical and functional properties. Crit. Rev. Food Sci. Nutr. 44:297-322. https://doi.org/10.1080/ 10408690490464041.

Trani, A., G. Gambacorta, P. Loizzo, A. Cassone, and M. Faccia. 2016. Short communication: Chemical and sensory characteristics of canestrato di moliterno cheese manufactured in spring. J. Dairy Sci. 99:6080-6085. https://doi.org/10.3168/jds.2016-10899 https:/ /www.ncbi.nlm.nih.gov/pubmed/27179855.

Vagenas, G., and I. G. Roussis. 2012. Fat-derived volatiles of various products of cows', ewes', and goats' milk. Int. J. Food Prop. 15:665-682. https://doi.org/10.1080/10942912.2010.498542.

van Den Dool, H., and P. Dec. Kratz. 1963. A generalization of the retention index system including linear temperature programmed gas-liquid partition chromatography. J. Chromatogr. 11:463-471. https://doi.org/10.1016/S0021-9673(01)80947-X.

Vazquez-Landaverde, P. A., J. A. Torres, and M. C. Qian. 2006. Effect of high-pressure- moderate-temperature processing on the volatile profile of milk. J. Agric. Food Chem. 54:9184-9192. https://doi .org/10.1021/jf061497k.
Vervoort, L., T. Grauwet, B. T. Kebede, I. Van der Plancken, R. Timmermans, M. Hendrickx, and A. Van Loey. 2012. Headspace fingerprinting as an untargeted approach to compare novel and traditional processing technologies: A case-study on orange juice pasteurisation. Food Chem. 134:2303-2312. https://doi.org/10 .1016/j.foodchem.2012.03.096.

Wishart, D. S. 2008. Metabolomics: Applications to food science and nutrition research. Trends Food Sci. Technol. 19:482-493. https:// doi.org/10.1016/j.tifs.2008.03.003.

Yue, J., Y. Zheng, Z. Liu, Y. Deng, Y. Jing, Y. Luo, W. Yu, and Y. Zhao. 2015. Characterization of volatile compounds in microfiltered pasteurized milk using solid-phase microextraction and GC $\times$ GC-TOFMS. Int. J. Food Prop. 18:2193-2212. https://doi .org/10.1080/10942912.2014.966389.

Zhao, Y., H. Chen, J. Feng, Z. Chen, and S. Cai. 2017. ${ }^{1}$ H NMR-based compositional identification of different powdered infant formulas. Food Chem. 230:164-173. https://doi.org/10.1016/j.foodchem .2017.03.020.

Zhu, D., B. Kebede, G. Chen, K. McComb, and R. Frew. 2020. Effects of the vat pasteurization process and refrigerated storage on the bovine milk metabolome. J. Dairy Sci. 103:2077-2088. https://doi .org/10.3168/jds.2019-17512.

\section{ORCIDS}

Lorraine Jane Sanchez ํ https://orcid.org/0000-0002-1704-7919

Dan Zhu (ㄴ) https://orcid.org/0000-0002-6136-1788

Russell Frew ำ https://orcid.org/0000-0002-6138-2116

Biniam Kebede ㄴ https://orcid.org/0000-0001-5774-9539 